\title{
A produção enxuta como fator diferencial na capacidade de fornecimento de PMEs
}

\author{
Maria Letícia Sousa Correia Lima, Doutoranda \\ Escola Politécnica da USP - Departamento de Engenharia de Produção \\ Paulo Antônio Zawislak, Dr. \\ PPGA/ EA/UFRGS
}

\begin{abstract}
Resumo
Face ao processo de reestruturação produtiva que a indústria automotiva brasileira tem vivenciado, notadamente a partir dos anos 1990, e à influência da filosofia enxuta de produção neste, o presente artigo traz um estudo realizado em pequenas e médias empresas (PMEs) gaúchas sobre o impacto potencial da aplicação de uma ferramenta da produção enxuta, o Mapeamento do Fluxo de Valor, na capacidade de fornecimento destas. Foram analisadas sete empresas no Estado. O resultado obtido foi uma redução geral nos tempos de estoques de $23 \%$, o mesmo ocorrendo para o tempo de agregação de valor, reduzido em 65\%. Pode-se dizer, portanto, que os ganhos potenciais com a aplicação das propostas apresentadas possibilitariam às empresas não somente fornecer de acordo com a demanda do cliente e em fluxo contínuo, mas também aumentar sua capacidade de fornecimento, atendendo às exigências de preço, prazo e flexibilidade.
\end{abstract}

\section{Palavras-chave}

Cadeia de suprimento, produção enxuta, Mapeamento do Fluxo de Valor.

\section{Lean production as a tool to improve the supply capability of the SMEs}

\begin{abstract}
The automotive industry, especially in the 90's, has been passed through a re-structure process of its productive base and supply relationship. Supporting such a process, there is a production philosophy coined lean production. This paper aims at pointing out some considerations about what could be done, regarding the production process, that may improve the supply capability of the autoparts firms in the RS state. Seven firms were analyzed and a lean production tool, the Value Stream Mapping, was applied. The results obtained were positive in all firms. The general stock reductions were of about 23\%. Concerning value addition the reductions were of about 65\%. Therefore, the potential gains from the implementation of the improvements suggested at Value Stream Map would make it possible not only to produce accordingly to the demand but also, to increase the supply capability of the firms.
\end{abstract}

\section{Key words}

Supply chain, lean production, Value Stream Mapping. 


\section{INTRODUĈ̣̃O}

As mudanças econômicas ocorridas notadamente na segunda metade do século vinte têm redesenhado as bases de competitividade industrial no mundo. Quesitos como qualidade e confiabilidade do produto, rapidez no atendimento às necessidades do mercado e flexibilidade, são considerados como as novas dimensões de sucesso empresarial.

De forma a atender estas dimensões, as empresas estabelecem processos de reestruturação interna - e.g. em suas práticas de gestão da produção - e externa - e.g. nas relações com seus clientes e fornecedores. $\mathrm{Na}$ indústria automotiva verifica-se que este processo de reestruturação possui como forte inspiração uma filosofia de organização da produção: a produção enxuta. que não as tradicionais da indústria automotiva nacional.

É neste cenário de alterações estruturais e realocações geográficas que se encontra o setor automotivo do Estado do Rio Grande do Sul.

Um dos mais importantes braços da indústria automotiva nacional, a cadeia automotiva gaúcha é composta por montadoras de veículos leves, ônibus, caminhões, máquinas agrícolas e veículos especiais e por um parque de micro, pequenas e médias empresas (PMEs) que compõem o setor de autopeças local. O predomínio de montadoras de veículos pesados confere às empresas do Estado qualificação e padrões de resposta às demandas dos clientes (principalmente nos quesitos preço e prazo) diferentes dos praticados pelas montadoras de veículos leves.

Tem-se desta forma, de um lado, um novo padrão de relacionamento sendo estabelecido, a cadeia enxuta, e de outro, mais especificamente no Rio Grande do Sul, um leque de PMEs do setor automotivo cujas características de fornecimento, em face de determinantes locais, são diferentes das empregadas nacionalmente. Como fazer, então, com que essas empresas atinjam padrões mais amplos de fornecimento?

A partir deste questionamento, foi realizado um estudo cujo objetivo foi o de

As desverticalizações das montadoras de veículos, que passaram a se concentrar nas etapas consideradas estratégicas e a delegar as demais a seus fornecedores, podem ser consideradas como manifestações deste processo de mudança no setor automotivo. O processo de mudança iniciou-se, portanto, a partir da empresa-mãe, mas tem progredido no sentido de abranger os demais elos da cadeia e alterar a própria estrutura e lógica de funcionamento desta. Assim, um novo padrão de relacionamento entre empresas e fornecedores tem sido estabelecido: a cadeia enxuta.

Esta cadeia pressupõe que seus membros trabalhem sob a mesma lógica de fornecimento (enxuto) e que exista uma integração entre os mesmos, traduzida na forma de um estreitamento nas relações de fornecimento e de parceria. Ela é um referencial teórico que procura possibilitar a coordenação das atividades dos vários elos em um fluxo contínuo, seguindo conforme as exigências e demandas do elo mais forte.

No Brasil, os reflexos das mudanças mundiais foram notados principalmente a partir dos anos 1990, com a abertura da economia e conseqüente maior exposição das empresas à concorrência internacional, com a renovação produtiva baseada em novas tecnologias, redução das estruturas das grandes empresas e terceirização de serviços, e com a migração de montadoras para outras regiões, identificar, com base nos conceitos enxutos, quais os pontos de melhoria no processo produtivo que proporcionariam às empresas fornecedoras de autopeças do Estado do Rio Grande do Sul uma diferenciação em sua capacidade de fornecimento que pudesse significar uma possível maior participação na cadeia automotiva local e nacional.

Para a identificação dos pontos de melhoria foi utilizada a ferramenta de Mapeamento do Fluxo de Valor. Esta ferramenta resume os princípios enxutos e visa analisar os fluxos de materiais e informações das empresas, de forma a visualizar como se dá a organização da produção e identificar os possíveis desperdícios no processo, bem como o que pode ser melhorado.

O presente artigo descreve, sucintamente, o resultado da pesquisa realizada em sete PMEs pertencentes à cadeia automotiva gaúcha, a partir da aplicação do Mapeamento do Fluxo de Valor, abordando as principais melhorias propostas e os ganhos potenciais.

\section{A PRODUC̣ÃO ENXUTA E A EXPANSÃO DO CONCEITO - A CADEIA ENXUTA}

O termo produção enxuta foi cunhado pela primeira vez por Krafcik (1988), membro do grupo de estudos do IMVP - International Motor Vehicle Program. Esta 
denominação foi criada para expressar um sistema de produção caracterizado pela eliminação progressiva do desperdício, pelo fluxo contínuo com que os processos produtivos ocorrem, pela produção segundo a demanda do cliente no tempo e na quantidade por este estabelecidos e, por fim, pela relação próxima e de parceria com fornecedores. Estes podem ser também denominados como os requisitos básicos que configuram um sistema enxuto de produção.

Como auxílio para o cumprimento destes requisitos, o sistema enxuto de produção disponibiliza uma relação de práticas que visam, de forma mais ampla, otimizar o leadtime (tempo demandado desde a entrada da matéria-prima na empresa até a saída do produto final), o tempo de agregação de valor (tempo em que o produto está sendo processado) e atender ao takt-time (ritmo de vendas, ou seja, quantas peças são demandadas por turno de trabalho).

Analisando a estrutura de empresas tradicionais e enxutas no Quadro 1 pode-se perceber, de forma mais clara, as mudanças que o estabelecimento do sistema enxuto propõe realizar.

Como se pode observar pelo Quadro 1, os itens referentes às relações com os clientes nas empresas tradicionais são idênticos aos do relacionamento destas empresas com seus fornecedores, o mesmo se dando com as empresas enxutas. Tal característica advém do fato de que as práticas estabelecidas a montante em uma cadeia de suprimentos acontecem sob as mesmas "regras" que as ocorridas a jusante. Porém, uma vez sendo alterada esta "regra", as relações também o são e a cadeia como um todo sofre modificação (WOMACK e JONES, 1998). Tem-se aqui o cerne da cadeia enxuta.

Uma vez operada segundo a lógica enxuta de produção, esta cadeia tem como base a integração entre os elos, ou seja, o estabelecimento de relações mais intensas e maiores níveis de confiança. Ela é um referencial teórico que procura coordenar as atividades de forma que os processos, dentro dos elos e entre eles, sigam em fluxo

Quadro 1: Diferenças entre culturas de negócios de empresas - modelo tradicional versus modelo enxuto. EMPRESA TRADICIONAL EMPRESA ENXUTA

\section{RELAÇÃO COM CLIENTE}

- Seleção baseada notadamente em preço;

- Não existência de compromisso de venda;

- Custos e riscos do lançamento de novos produtos sendo arcados pelas empresas.
- Negociação via preço, prazo e qualidade;

- Contratos de médio e longo prazo;

- Desenvolvimento conjunto de projetos, parceria entre cliente e empresa.

\section{PRODUÇÃo}

- Administração do tipo top-down (de cima para baixo], em que as ordens são fornecidas pelos altos níveis da empresa para a produção;

- Limitado envolvimento dos funcionários nas decisões;

- Produção baseada na previsão de vendas e pedidos fechados;

- Cultura de estoque de segurança como forma de absorver as oscilações do mercado e as falhas na previsão de vendas.
- Níveis hierárquicos mais baixos dotados de poder decisório quanto à produção, pois são os mesmos que estão em contato com as dificuldades encontradas no chão-de-fábrica;

- Busca contínua pela perfeição, melhoria contínua;

- Produção disparada pela demanda do cliente, na quantidade e tempo em que esta demanda ocorre;

- Preocupação em estabelecer um fluxo contínuo na produção, de forma a eliminar os estoques e desperdícios na produção.

\section{RELAÇÃO COM FORNECEDORES}

- Seleção baseada notadamente em preço;

- Não existência de compromisso de venda;

- Custos e riscos do lançamento de novos produtos sendo arcados pelas empresas.
- Negociação via preço, prazo e qualidade;

- Contratos de médio e longo prazo;

- Desenvolvimento conjunto de projetos, parceria entre cliente e empresa.

Fonte: Adaptado de Henderson e Larco (1999) e Rother e Shook (1998). 
contínuo, conforme as exigências e demandas do elo mais forte.

\section{As PMEs do setor de autopeças e a cadeia automotiva gaúcha}

O setor de autopeças, congregador das PMEs nacionais da cadeia automotiva, é composto por este segmento de empresas e por um leque de outras pequenas e médias filiais de grandes grupos estrangeiros, grandes empresas estrangeiras e grandes empresas de capital.

Como visto, tem-se um novo padrão de relacionamento procurando ser estabelecido na indústria automotiva, a cadeia enxuta, e com ele a ampliação do alcance dos padrões de exigências das montadoras para com seus fornecedores, e a necessidade de integração entre os membros da cadeia como forma de resposta às exigências.

No curso destas mudanças, o setor de autopeças apresenta-se heterogêneo, não apenas no tocante às transações que realiza com diferentes níveis da cadeia, mas também quanto à sua capacitação, no sentido de manter ou ampliar o fornecimento dentro da cadeia.

A absorção das mudanças pelos A que busca o fluxo contínuo dos processos elos da cadeia, notadamente os mais próximos da base, torna-se, desta forma, necessária e, uma vez as mudanças ocorrendo sob o enfoque da produção enxuta, pode-se

Assim como para as grandes montadoras, o ambiente de mudanças instalado, principalmente a partir da década de 90, tem atingido também o setor de autopeças. Estudos do BNDES (1996) apontaram que as PMEs que não vêm realizando investimentos significativos para modernização produtiva e gerencial serão as mais afetadas pela implementação da redução do número de fornecedores e pelos fortes requisitos demandados pelas montadoras e fornecedores diretos, reflexos diretos do processo de mudança. $\mathrm{O}$ estudo também traz que, embora dentro do setor como um todo exista um grupo de empresas que está investindo, notadamente as maiores ou as líderes de segmento ou exportadoras, existe a parcela de PMEs que necessitam investir, para ganhos de produtividade e qualidade e racionalização de operações, inclusive em relocalização de unidades, de forma a fazer parte da rede de fornecedores de montadoras e para que seja alcançada maior competitividade internacional. É neste cenário que se encontram as empresas do setor de autopeças gaúcho.

A cadeia automotiva gaúcha é composta de montadoras de veículos leves, ônibus, caminhões, máquinas agrícolas e veículos especiais e mais de 300 fornecedores, distribuídos nos segmentos de direção, suspensão e freios, eletroeletrônicos, fundidos, motor e transmissão, químicos, plásticos e borrachas, usinados e conformados. Existe no Estado um predomínio de montadoras de veículos pesados que reflete no perfil das empresas fornecedoras locais. As montadoras de veículos pesados possuem para com seus fornecedores requisitos de qualidade, preço e prazo. Entretanto, como suas escalas são bem menores que as de veículos leves, estas exigências não têm o mesmo impacto na qualificação do fornecedor, que as realizadas pelas montadoras de veículos leves (ZAWISLAK, 1999). pensar nesta filosofia também como base norteadora do processo de adaptação das empresas. Este foi o foco maior adotado para a realização da presente pesquisa.

\section{METODOLOGIA}

Foram entrevistadas sete empresas, em um estudo de múltiplos casos, escolhidas dentre as pertencentes ao cadastro da pesquisa CARS - Cadeia Automotiva do Rio Grande do Sul (ZAWISLAK, 2001). Esta pesquisa buscou desenhar a cadeia automotiva gaúcha em quesitos como capacidade produtiva e de fornecimento, qualidade, utilização de ferramentas da produção enxuta, entre outros. Fazem parte deste cadastro 211 empresas, todas localizadas no estado do Rio Grande do Sul e fornecedoras para a indústria automotiva local, nacional e internacional.

\section{Mapeamento do Fluxo de Valor - MFV}

Utilizando-se uma definição prática, pode-se afirmar que o Mapeamento do Fluxo de Valor (MFV) é uma ferramenta da produção enxuta que auxilia no planejamento de negócio e gerenciamento de processo nas empresas (ROTHER e SHOOK, 1998). Porém, analisandose a filosofia enxuta em si, ele representa na realidade uma das portas de entrada para a implantação do sistema enxuto de produção.

Seu funcionamento se dá sob a forma de coleta de dados, análise destes e propostas de melhorias. Com uma relação de informações sobre as demandas dos clientes, fornecimento de matéria-prima, processos produtivos, tempos de ciclos, setup de máquinas e estoques, além do número de pessoas envolvidas e a forma como os dados fluem na empresa, desenha-se um mapa que contempla de forma esquemática e organizada esses dados, o mapa 
do estado atual. A partir deste e tendo como mola mestra de todas as mudanças o cliente, ou seja, a demanda, utilizam-se os princípios e as práticas da produção enxuta para se trabalhar todo o fluxo de materiais e informação. As propostas são também desenhadas e compõem o mapa do estado futuro, e podem requerer desde alterações na organização da produção, como por exemplo, a criação de células de produção, até acordos com fornecedores para suprimento de matéria-prima em prazos menores, que reduziriam os estoques iniciais.

\section{Escolha das empresas e produtos}

As empresas escolhidas foram de pequeno ou médio porte, pertencentes ao setor de autopeças gaúcho. O porte da empresa seguiu a classificação do Sebrae (2001), que utiliza como critério o número de empregados, conforme a Tabela 1 .

As razões sociais das empresas e dos fornecedores e clientes, bem como as descrições detalhadas dos produtos estudados, foram omitidas, utilizando-se em seu lugar nomes fictícios e denominações genéricas de seus produtos. Esta troca não representou prejuízo para a compreensão do trabalho, uma vez que o foco principal do estudo residiu na organização da produção e no fluxo de materiais e informações, dentro das empresas e para com seus fornecedores e clientes. O Quadro 2 apresenta os nomes fictícios das empresas e os produtos estudados.

Para a seleção não foi levado em consideração se a empresa já fornecia diretamente para alguma montadora ou não. Tal fato não teve relevância, uma vez que se

Tabela 1: Classificação de empresas segundo o tamanho.

\begin{tabular}{|c|c|c|}
\hline \multirow{2}{*}{ CLASSIFICAÇÃO } & \multicolumn{2}{|c|}{ NÚMERO DE EMPREGADOS } \\
\cline { 2 - 3 } & INDÚSTRIA & 1 a 9 \\
\hline Micro & 1 a 19 & 10 a 49 \\
\hline Pequena & 20 a 99 & 50 a 99 \\
\hline Média & 100 a 499 & 100 e mais \\
\hline Grande & 500 e mais & \\
\hline
\end{tabular}

Fonte: Sebrae (2001)

Quadro 2: Empresas e produtos pesquisados.

\begin{tabular}{|c|c|}
\hline EMPRESAS & PRODUTO \\
\hline Borracha Ltda. & Bexiga \\
\hline Chapa Ltda. & Surdina \\
\hline Ferro Ltda. & Tomada de força \\
\hline Fibra Ltda. & Válvula de bóia \\
\hline Latão Ltda. & Chicote elétrico \\
\hline Cabo Ltda. & Carcaça filtro \\
\hline Plástico Ltda. & .
\end{tabular}

Tabela 2: Empresas pesquisadas e seus percentuais de fornecimento para a cadeia automotiva.

\begin{tabular}{|c|c|}
\hline EMPRESAS & PERGENTUA VENDAS PARA CADEIA AUTOMOTIVA \\
\hline Borracha Ltda. & Abaixo de 10\% \\
\hline Chapa Ltda. & Acima de $50 \%$ \\
\hline Ferro Ltda. & Entre 10 e $35 \%$ \\
\hline Fibra Ltda. & Acima de $50 \%$ \\
\hline Latão Ltda. & Acima de $50 \%$ \\
\hline Cabo Ltda. & Acima de $50 \%$ \\
\hline Plástico Ltda. & Abaixo de $10 \%$ \\
\hline
\end{tabular}


procurou observar no trabalho a potencialidade de aumento da capacidade de fornecimento (e conseqüentemente de produção) das empresas para a cadeia como um todo, não somente àquela pertencente atualmente. A Tabela 2 mostra os percentuais de destino das vendas de cada empresa estudada para a cadeia automotiva.

Os produtos foram escolhidos em conjunto pela pesquisadora e os representantes da empresa, tendo sido, entretanto, facultada a esta última a decisão final. Como em todas as entrevistas os processos produtivos eram comuns à grande maioria das peças, esse critério não foi considerado na escolha dos objetos de estudo. Desta forma, as alternativas para seleção da peça ficaram entre os produtos com maiores índices de defeitos durante a produção ou devolução do cliente e aqueles que representavam maior faturamento para a empresa. Todas as pesquisadas escolheram estudar os produtos de maior faturamento, devido à escassez de dados sobre defeitos e/ ou devoluções de clientes. Além de representar maior faturamento, o produto escolhido também obedeceu ao critério de ser destinado às empresas pertencentes à indústria automotiva. A única empresa a ter o produto estudado não relacionado à cadeia automotiva foi a Borracha Ltda., pois esta trabalha, para o setor automotivo, no sistema de peças sob encomenda e, quando da entre- vista, não havia pedidos ou peças na produção. Para o objetivo do presente estudo essa escolha foi válida, pois foi explorado, da mesma forma como nas outras empresas, o potencial de produção da pesquisada.

O Quadro 3 contém as principais características das empresas estudadas, o porte segundo número de funcionários, o mercado de atuação e os nível de fornecimento dentro da cadeia (GITHAY e BRESCIANI, 1998).

\section{Escolha da ferramenta de coleta de dados}

Composto em sua grande maioria por PMEs, o setor de autopeças gaúcho, palco do presente estudo, possui, segundo Zawislak (1999), uma relação de empresas com capacidade de fornecimento mas que, no entanto, apresentam relativa participação na cadeia automotiva gaúcha.

Pela Tabela 3 pode-se observar, em estudo realizado no Rio Grande do Sul (ZAWISLAK, 2001), que das 211 empresas pesquisadas, $123(58,29 \%)$ apresentavam mais de 50\% de suas vendas destinadas à cadeia automotiva e 74 eram candidatas a aumentar suas participações. O percentual de fornecimento abaixo de 10\%, 38 empresas $(18,01 \%)$, foi alto levando-se em consideração os resultados das outras faixas. Somente ele responde por $51,35 \%$ das 74 empresas, sendo este um forte indicativo desta "relativa" participação destas empresas na ca-

Quadro 3: Empresas pesquisadas - porte, mercado de atuação e níveis de fornecimento.

\begin{tabular}{|c|c|c|c|}
\hline EMPRESAS & $\begin{array}{c}\text { PORTE QUANTO AO } \\
\text { No DE FUNCIONÁRIOS }\end{array}$ & MERCADOS DE ATUAÇÃo & $\begin{array}{c}\text { NíVEL DE } \\
\text { FORNECIMENTO }\end{array}$ \\
\hline Borracha Ltda. & Pequena & Autopeças, Químicos e Plásticos, Revestimentos & 3o nível e reposição \\
\hline Chapa Ltda. & Pequena & Autopeças & Reposição \\
\hline Ferro Ltda. & Pequena & Autopeças & 3o nível e reposição \\
\hline Fibra Ltda. & Pequena & Autopeças & o nível e reposição \\
\hline Latão Ltda. & Pequena & Autopeças & 3o nível e reposição \\
\hline Cabo Ltda. & Média & Montadoras, Autopeças, Eletroeletrônicos & 1o e oo níveis \\
\hline Plástico Ltda. & Média & Autopeças, Linha Branca & 3o nível \\
\hline
\end{tabular}

Tabela 3: Número de empresas versus Percentual de fornecimento para a cadeia automotiva.

\begin{tabular}{|c|c|c|}
\hline PERCENTUAL VENDAS & No DE EMPRESAS & \% \\
\hline Abaixo de 10\% & 38 & 8,01 \\
\hline De 10\% a 25\% & 17 & 9,01 \\
\hline De 25\% a 50\% & 19 & 58,29 \\
\hline Acima de 50\% & 123 & 6,63 \\
\hline Não respostas & 14 & 100 \\
\hline Total & 211 & 06 \\
\hline
\end{tabular}

Fonte: Zawislak (2001). 
deia e da potencial capacidade de melhoria da mesma.

O Mapeamento do Fluxo de Valor (MFV) é uma ferramenta da produção enxuta que permite visualizar como estão estruturados a organização da produção e o relacionamento com clientes e fornecedores das empresas. Essa visão possibilita não somente a identificação de possíveis gargalos produtivos, mas uma reflexão sobre o que poderia ser modificado no sentido de diminuir desperdícios (entenda-se custos) e melhorar o todo. Por outro lado, pode-se dizer, de forma genérica, que o processo de "pensar" novas melhorias sempre foi considerado como oneroso no quesito financeiro e de tempo, sendo, portanto, descartado pelas empresas que não dispunham de tais recursos, notadamente as PMEs. Contrariando esta visão, o MFV possibilita uma coleta de informações rica, assim como disponibiliza uma relação de práticas enxutas flexíveis o suficiente para adaptação à realidade das empresas e que as auxiliem nas mudanças identificadas como necessárias e possíveis. Desta forma, a escolha da ferramenta do MFV veio ao encontro do proposto no presente estudo, que procurou focar nas PMEs e no aumento de sua capacidade de fornecimento via melhoria nos processos produtivos. Vale ressaltar que, apesar de possuir aplicação facilitada em virtude de expor quais dados seriam buscados, a ferramenta demanda bastante esforço intelectual daquele que a utiliza, uma vez que o pensar sobre o processo e as adaptações necessárias a cada empresa são o diferencial que se deseja obter.

O questionário semi-estruturado aplicado na pesquisa foi desenvolvido pela autora com base na metodologia de aplicação do MFV descrito em Rother e Shook (1998), tendo sido para tanto dividido em quatro tópicos (Quadro 4):

A divisão em quatro tópicos foi escolhida para facilitar a coleta de dados em campo e o posterior desenho dos fluxos de materiais e informações dos produtos estudados no mapa do estado atual. A relação entre os dados coletados e os fluxos está no Quadro 5.

\section{Quadro 4: Informações coletadas nas empresas.}

\section{DADOS GERAIS}

- Ano de fundação;

- Porte da empresa;

- Segmento dentro da cadeia automotiva;
- Percentual de vendas relacionado à cadeia automotiva;

- Mercados que atinge - local, nacional, internacional;

- Principais produtos.

\section{RELAÇÕES DE VENDAS - CLIENTE}

- Principais clientes;

- Quantidades médias vendidas;

- Freqüência de entrega;

- Freqüência de previsão de vendas;
- Freqüência de fechamento do pedido;

- Transporte do produto acabado;

- Embalagem do produto acabado.

\section{PRODUÇÃO}

- Produto;

- Etapas produtivas relacionadas ao produto em estudo: quais etapas e tempos de operação;

- Como ocorre o disparo da produção;

- Índices de refugo de peças;
- Layout da fábrica;

- Utilização de ferramentas de planejamento e controle da produção;

- Turnos de trabalho (número de turnos e quantidade de horas] e horas paradas (almoço e descanso).

\section{RELAÇÕES DE SUPRIMENTOS - FORNECEDOR}

- Principais matérias-primas;

- Transporte da matéria-prima;

- Embalagem da matéria-prima

- Principais fornecedores;
- Quantidades médias adquiridas;

- Freqüência de entrega;

- Freqüência de previsão de compras;

- Freqüência de fechamento do pedido.

Fonte: Elaborado a partir de Rother e Shook (1998). 
O tópico Dados Gerais teve o objetivo de caracterizar as empresas pesquisadas quanto a porte, ano de fundação, segmento a que pertence dentro da cadeia automotiva, além da participação das entrevistadas nesta cadeia e os mercados que atingem, não fazendo, portanto, parte dos fluxos de materiais ou informações.

\section{Coleta de dados}

Foram entrevistados funcionários das áreas de produção, qualidade, vendas e compras. As informações referentes aos dados gerais foram coletadas com os proprietários das empresas, diretores e gerentes. Para o delineamento das relações de vendas e suprimentos foram entrevistados os responsáveis pelos setores de vendas e com- pras, porém, como algumas entrevistadas não possuíam delimitações claras das funções administrativas, nestas o levantamento ocorreu a partir de um mesmo funcionário. Nos fluxos de materiais e informações da produção buscaram-se dados com os responsáveis pela produção e com os operários no chão-de-fábrica. Os tempos de ciclo das etapas produtivas observadas foram medidos pela pesquisadora; o tempo de setup foi obtido a partir de informações da empresa.

Depois de percorridas as áreas envolvidas e de coletadas as informações referentes aos quatro tópicos estudados (Quadro 4) com os respectivos responsáveis, foi desenhado o mapa do estado atual de cada empresa referente ao produto em estudo.

Quadro 5: Dados coletados - fluxos de materiais e informações.

\begin{tabular}{|c|c|c|c|}
\hline & RELAÇÃO DE VENDAS & PRODUÇÃO & RELAÇÃO DE SUPRIMENTOS \\
\hline $\begin{array}{l}\text { FLUXO DE } \\
\text { MATERIAIS }\end{array}$ & $\begin{array}{l}\text { - Quantidades médias } \\
\text { vendidas; } \\
\text { - Freqüência de entrega; } \\
\text { - Transporte do produto } \\
\text { acabado; } \\
\text { - Embalagem do produto } \\
\text { acabado. }\end{array}$ & $\begin{array}{l}\text { - Produto; } \\
\text { - Etapas produtivas } \\
\text { relacionadas ao produto em } \\
\text { estudo: quais etapas e } \\
\text { tempos de operação; } \\
\text { - Layout da fábrica. }\end{array}$ & $\begin{array}{l}\text { - Principais matérias-primas; } \\
\text { - Quantidades médias } \\
\text { adquiridas; } \\
\text { - Freqüência de entrega; } \\
\text { - Transporte da matéria- } \\
\text { prima; } \\
\text { - Embalagem da matéria- } \\
\text { prima. }\end{array}$ \\
\hline $\begin{array}{c}\text { FLUXO DE } \\
\text { INFORMAÇÕES }\end{array}$ & $\begin{array}{l}\text { - Principais clientes; } \\
\text { - Freqüência de previsão } \\
\text { de vendas; } \\
\text { - Freqüência de } \\
\text { fechamento do pedido. }\end{array}$ & $\begin{array}{l}\text { - Produto; } \\
\text { - Como ocorre o disparo da produção; } \\
\text { - Índices de refugo de peças; } \\
\text { - Utilização de ferramentas de } \\
\text { planejamento e controle da produção; } \\
\text { - Turnos de trabalho (número de } \\
\text { turnos e quantidade de horas] e } \\
\text { horas paradas (almoço e descanso]. }\end{array}$ & $\begin{array}{l}\text { - Principais matérias-primas } \\
\text { - Principais fornecedores; } \\
\text { - Freqüência de previsão de } \\
\text { vendas; } \\
\text { - Freqüência de fechamento } \\
\text { do pedido. }\end{array}$ \\
\hline
\end{tabular}

Tabela 4: Tempos de agregação de valor e takt-times atuais das empresas pesquisadas.

\begin{tabular}{|c|c|c|c|c|}
\hline EMPRESAS & $\begin{array}{c}\text { TEMPO DE } \\
\text { AGREGAÇÃO DE } \\
\text { VALOR (HH:MM:SS) }\end{array}$ & $\begin{array}{c}\text { TAKTIIME } \\
\text { (HH:MM:SS) }\end{array}$ & $\begin{array}{l}\text { DIFERENÇA } \\
\text { (HH:MM:SS) }\end{array}$ & $\begin{array}{c}\text { PRODUÇÃO } \\
\text { ATENDENDO RITMO } \\
\text { DAS VENDAS }\end{array}$ \\
\hline Borracha Ltda. & 77:47:00 & 08:48:00 & - 68:59:59 & Não \\
\hline Chapa Ltda. & 4:23:05 & 00:22:57 & - 4:00:08 & Não \\
\hline Ferro Ltda. & 25:32:30 & $14: 04: 48$ & - 11:27:42 & Não \\
\hline Fibra Ltda. & 1:36:00 & 04:24:00 & 2:48:00 & Sim \\
\hline Latão Ltda. & $0: 17: 16$ & 00:07:08 & - 0:10:08 & Não \\
\hline Cabo Ltda. & 0:04:20 & 01:28:00 & 1:23:40 & Sim \\
\hline Plástico Ltda. & 0:02:13 & 01:36:00 & $1: 33: 47$ & Sim \\
\hline
\end{tabular}


Além dos dados formais, durante a entrevista também eram levantadas informações sobre viabilidade de acordos com fornecedores e clientes com relação a freqüência de entrega, criação de células de produção, mudanças no layout de fábrica, compra ou troca de equipamentos e remanejo de pessoal entre as etapas produtivas. Estas informações, juntamente com os princípios e práticas da produção enxuta contidos na metodologia de Mapeamento do Fluxo de Valor, balizaram as propostas de melhorias, expostas novamente de forma esquemática por meio do mapa do estado futuro.

No mapa do estado futuro procurou-se otimizar o lead-time e o tempo de agregação de valor, de forma a atender o takt-time do produto estudado. A escolha destes medidores de desempenho da produção deve-se à estreita relação dos mesmos com a capacidade de fornecimento da empresa.

\section{RESULTADOS}

\section{Principais dificuldades identificadas}

A partir da análise do takt-time verificou-se que das sete empresas entrevistadas, três estavam conseguindo produzir de forma a atender a demanda do cliente, sendo que duas destas operavam em sistema de kanban com seus principais clientes. As quatro empresas restantes apresentaram tempos de agregação de valor superiores ao takt-time, ou seja, em um período de tempo estabelecido, devido ao elevado tempo de agregação de valor da linha, não é possível produzir a quantidade de unidades necessárias para atender o ritmo de vendas, gerando, desta forma, estoques intermediários e finais para que as entregas ocorram dentro do prazo.

A Tabela 4 apresenta os tempos de agregação de valor e takt-times das entrevistadas. Em negrito, as empresas cujo tempo e agregação de valor foi inferior ao takt-time.
Algumas empresas apresentaram valores de lead-time bastante elevados, como se pode constatar pela Tabela 5, tendo sido o estoque intermediário a principal causa de tal resultado. Este responde por cerca de $66 \%$ do leadtime quando se analisa as empresas agrupadas, cabendo ao estoque inicial $27 \%$ deste total e, ao final, $7 \%$. A única pesquisada a apresentar maior valor para o estoque final

Tabela 5: Lead-time das empresas pesquisadas.

\begin{tabular}{|c|c|c|c|c|}
\hline \multirow{2}{*}{ EMPRESAS } & \multirow{2}{*}{$\begin{array}{c}\text { LEAD TIME } \\
\text { (DIA) }\end{array}$} & \multicolumn{2}{|c|}{ ESTOQUES (DIA) } \\
\cline { 2 - 5 } & & INICIAL & INTERMEDIÁRIO & FINAL \\
\hline Borracha Ltda. & 74,88 & 12,71 & 62,17 & 0 \\
\hline Chapa Ltda. & 10,38 & 3 & 5,91 & 1,47 \\
\hline Ferro Ltda. & 180,8 & 41,6 & 139,2 & 0 \\
\hline Fibra Ltda. & $\mathbf{2 3 , 1}$ & $\mathbf{2 1 , 1}$ & $\mathbf{1 , 5}$ & $\mathbf{0 , 5}$ \\
\hline Latão Ltda. & 31,22 & 10,9 & 11 & $\mathbf{0}, 32$ \\
\hline Cabo Ltda. & $\mathbf{0 , 7 9}$ & $\mathbf{0 , 5}$ & $\mathbf{0 , 2 9}$ & $\mathbf{0}$ \\
\hline Plástico Ltda. & $\mathbf{1 2 , 3}$ & $\mathbf{0}$ & $\mathbf{1 2 , 3}$ \\
\hline
\end{tabular}


Plástico Ltda, cujo processo produtivo é bastante enxuto.

O Quadro 6 resume as principais características dos fluxos de materiais e informações das sete empresas entrevistadas.

A principal dificuldade identificada na relação cliente-empresa encontrava-se no fato de o fechamento do pedido ser estabelecido, principalmente, com base em preço. Esta característica, aliada à negociação de pequenos lotes de peças por pedido, diminui o poder de negociação das empresas, que fica restrito a, basicamente, baixar os preços na medida em que isto não comprometa a empresa e a qualidade do produto. Observou-se, com isto, que as exigências por parte dos clientes, verificadas nas entrevistas, foram as mesmas identificadas na pesquisa CARS (ZAWISLAK, 2001), na qual o item padrões internacionais de custo, qualidade, quantidade e preço obteve $75,3 \%$ das respostas e flexibilidade de fornecimento para alterar prazos de entrega e produtos, $64,9 \%$. Segundo as entrevistadas, seus clientes escolhem as empresas primeiro buscando por "preço" e somente depois, dentre aquelas de melhor oferta, é verificada a de maior "qualidade". Caso não se tenha alcançado o necessário neste quesito, os valores aceitáveis de preço são ampliados e inicia-se novamente a procura.

A existência de contratos de fornecimento de médio e longo prazo sequer foi cogitada pelas empresas, exceto a Cabo Ltda. que fornece para uma montadora. Para esta, um contrato seria um compromisso de parceria onde ambas as partes sairiam ganhando. As demais empresas alegaram que isto não era prática corrente para elas e que não acreditavam nesta possível "nova" realidade.

O principal problema apontado na relação com os

Quadro 6: Principais características dos fluxos de materiais e informações nas empresas pesquisadas.

\begin{tabular}{|c|c|c|}
\hline EMPRESAS & FLUXO DE MATERIAIS & FLUXO DE INFORMAÇÕES \\
\hline Borracha Ltda. & $\begin{array}{l}\text { - Cultura de estoque de segurança; } \\
\text { - Lead-time elevado - estoques inicial e } \\
\text { intermediário; } \\
\text { - Layout da fábrica não otimizado; } \\
\text { - Setup elevado - } 5 \text { h, um equipamento. }\end{array}$ & $\begin{array}{l}\text { - Processo parte formal (ordem de serviço) } \\
\text { e informal; } \\
\text { - Disparo da produção na } 1 \text { å etapa do } \\
\text { processo. }\end{array}$ \\
\hline Chapa Ltda. & $\begin{array}{l}\text { - Cultura de estoque de segurança; } \\
\text { - Lead-time relativamente elevado - } \\
\text { estoques intermediários; } \\
\text { - Layout da fábrica não otimizado. }\end{array}$ & $\begin{array}{l}\text { - Processo formal (ordem de serviço]; } \\
\text { - Parte das informações correm em fluxo } \\
\text { contínuo; } \\
\text { - Disparo da produção na 1a etapa do processo. }\end{array}$ \\
\hline Ferro Ltda & $\begin{array}{l}\text { - Cultura de estoque de segurança; } \\
\text { - Lead time - estoques inicial e intermediário; } \\
\text { - Organização da produção; } \\
\text { - Setup elevado - 1,5 h, um equipamento. }\end{array}$ & $\begin{array}{l}\text { - Processo formal (planilha eletrônica); } \\
\text { - Disparo da produção na etapa } \\
\text { intermediária - montagem }\end{array}$ \\
\hline Fibra Ltda. & $\begin{array}{l}\text { - Cultura de estoque de segurança; } \\
\text { - Lead-time - estoques inicial e intermediário; } \\
\text { - Organização da produção. }\end{array}$ & $\begin{array}{l}\text { - Processo formal (ordem de produção); } \\
\text { - Disparo da produção na 1a etapa do } \\
\text { processo. }\end{array}$ \\
\hline Latão Ltda. & $\begin{array}{l}\text { - Cultura de estoque de segurança; } \\
\text { - Lead-time - estoques inicial e final; } \\
\text { - Layout da fábrica não otimizado; } \\
\text { - Setup elevado - 4,5 h, um equipamento. }\end{array}$ & $\begin{array}{l}\text { - Processo parte formal (planilha eletrônica) } \\
\text { e informal; } \\
\text { - Disparo da produção na 1a etapa do } \\
\text { processo. }\end{array}$ \\
\hline Cabo Ltda. & $\begin{array}{l}\text { - Cultura de estoque de segurança; } \\
\text { - Organização da produção - puxada e } \\
\text { empurrada. }\end{array}$ & $\begin{array}{l}\text { - Processo formal (kanban e planilha } \\
\text { eletrônica); } \\
\text { - Disparo da produção na expedição. }\end{array}$ \\
\hline Plástico Ltda. & $\begin{array}{l}\text { - Cultura de estoque de segurança; } \\
\text { - Lead-time - estoques inicial e final; } \\
\text { - Setup elevado - } 2 \text { h, um equipamento. }\end{array}$ & $\begin{array}{l}\text { - Processo formal (ordem de serviço); } \\
\text { - Disparo da produção na 1a etapa. }\end{array}$ \\
\hline
\end{tabular}


fornecedores foi, da mesma forma como ocorrido com os clientes, o pequeno poder de negociação devido aos baixos volumes de materiais adquiridos.

Algumas pesquisadas alegaram que possuem como fornecedores grandes empresas de fora do Estado, o que inviabiliza a compra de pequenas quantidades, com conseqüente maior número de entregas, em virtude do preço do frete e do próprio produto.

Apesar da dificuldade inicial colocada, à medida que o fluxo produtivo era discutido durante a entrevista, as empresas apresentaram uma certa abertura no tocante a um possível acordo com os fornecedores. Esta constatação pode indicar que os atuais prazos de entrega talvez ocorram muito mais em função de uma não-estruturação interna da empresa, no sentido de diminuir seus estoques ou otimizar seus processos, do que por restrições dos fornecedores.

\section{Principais melhorias propostas}

As melhorias propostas em todos os casos estudados tiveram como base os pontos de desperdício identificados por meio do mapeamento dos fluxos atuais de informação e material e as ferramentas disponibilizadas pela produção enxuta. Uma vez desenhados os mapas atuais, e de posse das ferramentas do MFV e das informações coletadas na empresa, desenhou-se o que poderia ser o mapa futuro, calculando-se novamente seus indicadores (lead-time, tempo de agregação de valor e takt-time) e comparando-os com os atuais. O princípio norteador utilizado foi o de tornar o fluxo de produção contínuo, puxado pelo cliente, ou seja, nos casos estudados, a partir da solicitação da área de expedição, e de forma a atender o ritmo de vendas. Para tanto foram sugeridos acordos com fornecedores e clientes e alterações na organização da produção.

No relacionamento com clientes, apenas três empresas necessitariam de uma diminuição na freqüência de entrega. Para alterações no relacionamento com fornecedores o número de empresas aumenta: são quatro as que precisariam de um acordo para mudanças nos padrões de fornecimento.

O processo produtivo sofreu melhorias no sentido de adequar o tempo de agregação de valor ao takt-time (produzir conforme o ritmo de vendas), reduzir os leadtime e melhorar o fluxo de informações.

A criação de supermercados (pontos de estoque controlados nos quesitos tempo de armazenagem e quantidade de unidades) em substituição ao estoque de matériaprima e produtos acabados, e como mecanismo de união das etapas que não puderam ser agrupadas em células, foi proposta para todas as empresas. Outro dispositivo usado em todas as entrevistadas foi o disparo da produção ocorrendo na expedição, o que caracteriza a produção puxada pelo cliente.

A criação de células, agrupando etapas consecutivas com tempos de ciclos semelhantes e cujos tempos de setup fossem os mínimos, foi utilizada em seis empresas. Estas empresas apresentaram também fluxo contínuo em parte de sua produção, o que facilitou a implantação das células.

A necessidade de elaboração de mix de produtos foi feita para cinco entrevistadas. Com exceção de uma delas, todas as demais apresentaram problemas no tempo de setup de um de seus equipamentos. Tanto o mix quanto a redução do tempo de setup foram propostos na forma de kaizens, uma vez que sua definição passaria por um estudo dos tempos de ciclos do maquinário, dos próprios tempos de setup e dos lotes mínimos de produção, que exigiria um maior conhecimento do processo produtivo de cada empresa e uma discussão mais detalhada sobre o mesmo.

Para o fluxo de informações foi utilizado o sistema de kanban interno em todas as empresas, com a produção sendo disparada pela expedição e o processo correndo em fluxo por meio de supermercados e células de trabalho, as informações sobre o que produzir e quando seriam repassadas pela retirada e colocação dos cartões ou sinalizações do kanban. O mesmo ocorreria com relação ao

Tabela 6: Lead-time atuais e futuros.

\begin{tabular}{|c|c|c|c|}
\hline EMPRESAS & $\begin{array}{c}\text { LEAD-TIME ATUAL } \\
\text { (DIA) }\end{array}$ & $\begin{array}{c}\text { LEAD-TIME FUTURO } \\
\text { (DIA) }\end{array}$ & $\begin{array}{c}\text { REDUÇÃO } \\
\text { (\%) }\end{array}$ \\
\hline Borracha Ltda. & 74,88 & 8 & 89,32 \\
\hline Chapa Ltda. & 10,38 & 10,2 & 1,73 \\
\hline Ferro Ltda. & 180,8 & 22,5 & 87,56 \\
\hline Fibra Ltda. & 23,1 & 19 & 17,75 \\
\hline Latão Ltda. & 31,22 & 15,5 & 50,35 \\
\hline Cabo Ltda. & 0,79 & 1,6 & $\mathbf{1 0 2 , 5 3}$ \\
\hline Plástico Ltda. & 12,3 & 10 & 18,7 \\
\hline
\end{tabular}

${ }^{1}$ Para a empresa Cabo Ltda. houve acréscimo no lead time. 
pedido junto ao fornecedor, disparado a partir da retirada do kanban do supermercado de matéria-prima. Para os clientes, o fluxo permaneceria idêntico, alterando-se apenas a freqüência de entrega em algumas empresas.
A diferença média obtida no lead-time seria de $73,97 \%$, com as maiores diferenças observadas nas empresas Borracha Ltda. $(89,32 \%)$ e Ferro Ltda. $(87,56 \%)$, ambas também com os valores atuais de lead-time mais elevados. A única empresa a apresentar uma diferença negativa foi a Cabo Ltda. Nesta, o aumento foi devido ao dimensionamento do supermercado de matéria-prima para um dia de operação, sendo que este valor pode ser reduzido a qualquer momento em virtude do fornecedor trabalhar, também, em sistema kanban.

Estes valores de lead-time e tempo de agregação de valor, porém, não refletem o real ganho na capacidade de resposta ao cliente. A reestruturação produtiva com a implantação das melhorias possibilitaria que, uma vez a peça encontrando-se no supermercado final (expedição), o envio desta para o cliente seria imediato, apenas se buscaria no local próprio a quantidade demandada e todo processo seria disparado. Esta velocidade de atendimento à necessidade do cliente, no momento em que esta acontecer, pode ser considerada como um dos maiores diferenciais na capacidade de fornecimento que as propostas aqui feitas poderiam possibilitar.

\section{CONCLUSÕES}

Como colocado anteriormente, existe na indústria automotiva um processo de reestruturação sistêmica ocorrendo sob o paradigma de produção vigente, a produção enxuta (CARDOSO, 1998). Este processo tem ultrapassado a esfera da empresa e cada vez mais está procurando atingir a cadeia de fornecimento, de forma a exigir uma maior integração entre os elos.

Analisando a cadeia automotiva, percebe-se que esta

lead-time das empresas.

Tabela 7 Resultados obtidos - impacto no potencial de fornecimento.

\begin{tabular}{|c|c|c|c|c|c|c|c|}
\hline EMPRESAS & $\begin{array}{c}\text { LEAD TIME } \\
\text { ATUAL } \\
\text { (DIA) }\end{array}$ & $\begin{array}{c}\text { LEAD TIME } \\
\text { FUTURO } \\
\text { (DIA) }\end{array}$ & $\begin{array}{c}\text { REDUçÃO } \\
\text { (\%) }\end{array}$ & $\begin{array}{c}\text { TEMPO DE } \\
\text { AGREG. DE } \\
\text { VALOR } \\
\text { ATUAL } \\
\text { (HH:MM:S5) }\end{array}$ & $\begin{array}{c}\text { TEMPO DE } \\
\text { AGREG. DE } \\
\text { VALOR } \\
\text { FUTURO } \\
\text { (HH:MM:SS) }\end{array}$ & $\begin{array}{c}\text { REDUÇÃo } \\
\text { (\%)] }\end{array}$ & $\begin{array}{c}\text { TAKT TIME } \\
\text { (HH:MM:SS) }\end{array}$ \\
\hline Borracha Ltda. & 74,88 & 8 & 89,32 & $77: 47: 00$ & $05: 25: 00$ & 93,04 & $08: 48: 00$ \\
\hline Chapa Ltda. & 10,38 & 10,2 & 1,73 & $04: 28: 05$ & $00: 21: 31$ & 91,82 & $00: 22: 57$ \\
\hline Ferro Ltda. & 180,8 & 22,5 & 87,56 & $18: 45: 19$ & $01: 09: 19$ & 93,84 & $14: 04: 48$ \\
\hline Fibra Ltda. & $\mathbf{2 3 , 1}$ & $\mathbf{1 9}$ & $\mathbf{1 7 , 7 5}$ & $\mathbf{0 1 : 3 6 : 0 0}$ & $\mathbf{0 0 : 5 0 : 0 0}$ & $\mathbf{4 7 , 9 2}$ & $\mathbf{0 4}: 24: 00$ \\
\hline Latão Ltda. & 31,22 & 15,5 & 50,35 & $00: 17: 16$ & $00: 06: 22$ & 63,13 & $00: 07: 08$ \\
\hline Cabo Ltda. & $\mathbf{0 , 7 9}$ & $\mathbf{1 , 6}$ & $\mathbf{- 1 0 2 , 5 3}$ & $\mathbf{0 0 : 0 4 : 2 0}$ & $\mathbf{0 0 : 0 0 : 9 0}$ & $\mathbf{6 5 , 3 8}$ & $\mathbf{0 1 : 2 8 : 0 0}$ \\
\hline Plástico Ltda. & $\mathbf{1 2 , 3}$ & $\mathbf{1 0}$ & $\mathbf{1 8 , 7}$ & $\mathbf{0 0 : 0 2 : 1 3}$ & $\mathbf{0 0 : 0 2 : 1 3}$ & 0 & $\mathbf{0 1 : 3 6 : 0 0}$ \\
\hline
\end{tabular}


integração tem ocorrido mais intensamente entre montadoras e fornecedores diretos. Estudos de Cooper e Ellram (1993) e Arkader (1997) verificaram que as práticas enxutas ocorriam entre montadoras e fornecedores diretos, mas para os demais elos não existia uma preocupação em coordenar as atividades.

Considerada como grande mercado produtor automotivo no Brasil, o parque de montadoras e fornecedores de autopeças instalado no Estado do Rio Grande do Sul não está fora desta realidade. Formado em sua maioria por empresas de micro, pequeno e médio porte, a indústria de autopeças gaúcha vem sofrendo as pressões nacionais e internacionais por qualidade, preço, flexibilidade e confiabilidade de seus produtos, porém, em sua resposta, pouco tem adotado da filosofia enxuta.

As sete empresas analisadas neste trabalho, todas pertencentes ao setor de autopeças gaúcho, não representam uma amostra significativa que possa fornecer um diagnóstico da cadeia. Ela aspira ser um indicativo, notadamente para as empresas do setor que ainda não adotam as práticas do fornecimento e produção enxuta, de como esse processo de mudança em curso na cadeia automotiva poderia ser traduzido e absorvido por todos e os ganhos potenciais que poderiam advir com sua aplicação.

Neste sentido, o uso da ferramenta de Mapeamento do Fluxo de Valor (MFV) foi de extrema importância. Síntese dos princípios e práticas enxutas, esta ferramenta promove o que pode ser chamado de "raio X" da empresa, uma vez que abrange diagnósticos e propostas de melhorias.

Dos processos analisados, o estoque foi o grande vilão. Considerada como necessária, todas as empresas, mesmo as mais enxutas, adotavam a estratégia de estoque de segurança. Algumas alegaram sua prática para garantir preços mais competitivos (pela formação de grandes lotes de compra) com seus fornecedores, outras, para cumprir uma previsão de vendas falha, face às oscilações do mercado, e a maioria colocou ambos como justificativa. O mesmo fato ocorreu nesta pesquisa, na qual as empresas alegaram que, devido aos baixos volumes mensais de compras, optaram por arcar com os custos de um alto estoque de matéria-prima, em um mecanismo de "compensação" pelos preços mais baixos obtidos na transação.

O resultado que seria obtido caso as melhorias propostas fossem implementadas, via MFV, foi positivo para todas as empresas. Em algumas o lado operacional respondeu mais forte, com reduções nos tempos de estoques, que chegariam a quase $90 \%$, e em outras, foi o de relacionamento que prevaleceu. Vale ressaltar que estes resultados tiveram como base, em um primeiro momento, a identificação do estado atual da empresa, para em seguida acontecer o exercício de "pensar" sobre o que poderia ser alterado para que os três indicadores que nortearam a pesquisa - lead-time, tempo de agregação de valor e takt-time - pudessem ser otimizados.

Pode-se dizer, então, que os ganhos potenciais com a aplicação das propostas apresentadas possibilitariam às empresas não somente fornecer de acordo com a demanda do cliente e em fluxo contínuo, mas também aumentar sua capacidade de fornecimento, atendendo às exigências de preço, via redução de custos com a eliminação de desperdício, e prazo e flexibilidade, via processos produtivos contínuos e otimizados.

\section{Edição especial início $07 / 03 / 2003$ fim $25 / 08 / 2003$}

\section{- Bibliografia}

\begin{abstract}
ARKADER, R. Relações de fornecimento no contexto de produção enxuta: um estudo da indústria automobilística brasileira. Rio de Janeiro, Tese (Doutorado) - Instituto de Pós-Graduação e Pesquisa em Administração-COPPEAD da Universidade Federal do Rio de Janeiro, 1997.

BNDES - Banco Nacional de Desenvolvimento Econômico e Social. Qualidade e produtividade na indústria brasileira. Rio de Janeiro: BNDES, Cni, SEBRAE, 1996.
\end{abstract}

CARDOSO, A. M. Trabalhar, verbo transitivo: trajetórias ocupacionais de trabalhadores da indústria automobilística. Dados, vol. 41, n. 4, 1998.
COOPER, M. C. \& ELLRAM, L. M., Characteristics of Supply Chain Management and Implications for Purchasing and Logistics Strategy. The International Journal of Logistics Management, Vol. 4, No. 2, 1993.

GITHAY, L., BRESCIANI, L. P. Texto para discussão. DPCT/IG/Unicamp, 1998.

HENDERSON, B. A., LARCO, J. L. Lean Transformation: how to change your business into a lean enterprise. Richmond: Editora Oaklea Press, 1999.
KRAFCIK, J. F. Triumph of the lean production system. Sloan Management Review, Vol. 30, n. 1, 1988.

ROTHER, M., SHOOK, J. Aprendendo a Enxergar. Mapeando o fluxo de valor para agregar valor e eliminar desperdício. São Paulo: Lean Institute Brasil, 1998.

SEBRAE - Serviço Brasileiro de Apoio às Micro e Pequenas Empresas. Benefícios oferecidos pelas MPE aos empregados. Disponível na internet URL: http// www.sebrae.org.br. 19/Outubro/2001.
WOMACK, J. P., JONES, D. T. A mentalidade Enxuta nas Empresas: elimine o desperdício e crie riqueza. Rio de Janeiro: Campus, 1998.

ZAWISLAK, P. A. (coord.). Diagnóstico Automotivo: A Plataforma Tecnológica da Cadeia Automotiva do RS. Porto Alegre: UFRGS/PPGA/NITEC/FIERGS, 1999.

Projeto CARS 2000. Disponível na internet URL: http//www.ppga.ufrgs.br/gcars. 30/ dezembro/2001. 